\title{
Stress: Concepts, theoretical models and nursing interventions
}

\author{
Ioanna V. Papathanasiou ${ }^{1,}{ }^{*}$, Konstantinos Tsaras ${ }^{1}$, Anna Neroliatsiou ${ }^{2}$, Aikaterini Roupa ${ }^{1}$ \\ ${ }^{1}$ Nursing Department, Technological Educational Institute of Thessaly, Larissa, Greece \\ ${ }^{2}$ Psychiatric Department, University Hospital of Larissa, Larissa, Greece
}

\section{Email address:}

iopapathanasiou@yahoo.gr (Papathanasiou I. V.), ktsa@teilar.gr (Tsaras K.), anna.neroliatsiou.sweet@gmail.com (Neroliatsiou A.), aikateriniroupa@gmail.com (Roupa A.)

\section{To cite this article:}

Ioanna V. Papathanasiou, Konstantinos Tsaras, Anna Neroliatsiou, Aikaterini Roupa. Stress: Concepts, Theoretical Models and Nursing Interventions. American Journal of Nursing Science. Special Issue: Mental Health Care: Aspects, Challenges and Perspectives.

Vol. 4, No. 2-1, 2015, pp. 45-50. doi: 10.11648/j.ajns.s.2015040201.19

\begin{abstract}
Stress is a fact of everyday life and it can be defined either as a reaction or as a stimulus. Over the years and with the progress of science many factors have been identified as sources of stress, such as Biological, Chemicals, Microbial, Psychological, Developmental, Socio-cultural and Environmental. Propose of this study is to present the basic concepts and the main theoretical models of stress, its effects on the individual, the coping strategies and the nursing methods of addressing it. The main theoretical approaches for stress are interpreting it differently, either as a stimulus, as a response or as a transaction. Nurses, after the recognition of patients' needs and reactions, should choose those interventions that will be the most effective for each particular patient. Most important interventions for alleviating stress are: anxiety reduction, anger management, relaxation and sleep, proper diet, physical exercise, relaxation techniques and effective time management.
\end{abstract}

Keywords: Stress, Concept of Stress, Theories of Stress, Stress Results, Nursing Interventions

\section{Introduction}

The term of Stress was first used back in the 17th century as to describe the "sorrow, suppression, discomfort and adversity" [1]. In the 19th century the term was reformed and among other, had the meaning of a strong influence exerted on a physical object or on a person [2].

Now days it can be said, that stress is a global phenomenon and it is the result of positives or negatives life's experiences [3]. The concept of stress is significant because it provides a way of understanding the person as a whole in life's various changes [4].

Propose of this study is to present the basic concepts and the main theoretical models of stress, its effects on the individual, the coping strategies and the nursing methods of addressing it.

\section{Concept of Stress}

Stress is defined either as a reaction or as a stimulus[1]. As a reaction the meaning of stress is consubstantial with specific changes that human biological system is experiencing [5].As stimulus, the definition of stress is related to environmental events that cause those changes. The stressful events can be acute, chronic, remitting and continuous chronic form [6].

\section{Stress Sources}

There are many sources of stress [7]. Some examples of stressful stimulus are listed below [2].

Biological: illness, surgery, pain, exposure to excessive cold or heat, intense muscle activity, sensory overload (e.g. noise pollution), accident.

Chemicals: medications, toxic substances, contaminated food and water.

Microbial: viruses, bacteria, parasites.

Psychological: real,fantastic or predicted unpleasant events e.g. illness, death, separation, divorce, failure, unpleasant feelings of fear, anger, internal conflict, threats to self-esteem and body image, feelings of inadequacy, addiction and worthlessness. 
Developmental: Premature birth, anatomical defects, growth inhibition, childhood or thirdage.

Socio-cultural: disturbed interpersonal relationships, social competition, business pressures, and economic difficulties, rapid changes in social and moral values, immigration, relocation, removal, and hospitalization.

Environmental: unemployment, air pollution, urban life, natural disasters, war, unhealthy residence extreme weather conditions.

One person can assess an event as stressful, while for another person is not [8]. Furthermore, the same person considers one event as stressful sometimes, while under other conditions the same eventcannot charge him emotionally [9]. Although there are situations that can affect most of the people, everyone seems to interpreting and assessing each situation according to its own subjective criteria and addresses it by his own unique way $[10,11]$.

Stress factors can broadly classified as internal or external, developmental and circumstantial. Internal stressors are generated within the person, for example a cancer. External stressors are generated outside the individual, for example a death in the family.Developmental stressors appear on predictable times during the life of the individual and circumstantial stressors are unpredictable and may appear at any time ofone's life (death, marriage, divorce). The extent to which some of these events can have positive or negative effects depend mainly on the individual's developmental stage [12].

\section{Main Theories about Stress}

The theoretical models that have been formulated for interpreting stress are helping to identify stressors in a particular situation and predicting the possibility of an individual's adaptation to stressful situation [13]. Three are the main theoretical approaches for stress, each one interprets stress differently either as a stimulus, as a response or s a transaction.

\subsection{Stimulus Based Models}

In these models the stress is interpreted as a stimulus, a life event or a group circumstances which may awakens normal and / or psychological reactions, which may increase the vulnerability of the individual to disease. According to Holmes, there are 43 life events or lifestyle changes, which can cause stress [7].According to this theory, both positive and negative life events are considered stressful.The scale of stressful life events is used to record the recent stressful experience of the individual, such as divorce, pregnancy, retirement [7].Ever since similar scales have been developed, however they should be used with caution,since the extent of stress, which is embodied to life events depends on the way in which is interpreted by the individual. Moreover, those scales must have beenvalidated in the age and in thesocioeconomic status, in addition they must have been cultural adapted [14].

\subsection{Response Based Models}

In those theoretical models, stress is interpreted as a response. The definition of stress as a response was developed and described by Selye, who defined stress as a nonspecific response of the body to any kind demands applied on it $[15,16]$.

Selye's model is called General Adaptation Syndrome (GAS).Selyein order todifferentiate the cause of stress from the response to this introduced the term " stressor" naming so any factor can cause stress and affect the balance of the individual [16,17].Selye mentions, due the fact that stress is a state of the body, it can only observed within the changes occurring in it [18]. This full body response general adaptation syndrome, (GAS) is manifested by releasing certain hormones, which resulted is changes in the structure and chemical composition of the body [16,18]. Apart from the adaption of the whole body, it is possible a portion reaction of the body or of an organ to take place. This response to stress is called local adaptation syndrome - LAS [18].

\subsection{Transaction Based Models}

All theoretical models that interpret stress as a transaction are based on the theory of Lazarus, who focused on the fact that there are differences among people in interpretation of stress as a stimulus or as a response [19]. None of the previous theories, according to Lazarus, could exactly explain which factors may lead some people to manage stress properly, while others are not, he stated that there is a lack in theories into the interpretation of the factors that help some people to adjust for a longer period than others in to a stressful stimuli [20].

Despite the fact that Lazarus acknowledges certain environmental conditions as causes of stress for many individuals, however, points out that people and groups of people differ in sensitivity and vulnerability to certain types of events, as well as in the interpretation and in the respond to those events [21]. For the interpretation of the diversity among individuals that are experiencing similar stressful events, Lazarus model is taking into account the cognitive processes that mediate between stimulus and response, as well as the factors affecting these processes [22].

Lazarus cognitive evaluation theory focuses on the individual, the environment and on the simultaneous cognitive evaluation of environmental demands and stimulus response options [20]. According to this theory, a number of external and internal information arriving daily in the neurocognitive level of the body which are interpreted by the process of cognitive evaluation [23,24].Cognitive evaluation is the process of judgment by which,the level of adjustment methods available that each person has, is recognized. It includes identifying available resources and options, which will help the person to negotiate with potential or actual demands [19].Upon the initial requirements evaluation, some can be assessed as irrelevant, and other as very stressful or as positive. Stress according to this theory is a process in which 
requirements outweigh the adaptive capacities of the individual. The requirements can be either external or internal [22].

In second stage, the evaluation is about the identification of sources and options that the individual has at his disposal. The reassessment is necessary and is the process of continuous redefinition of cognitive evaluation.Factors that influencing the evaluation of the identification can divided into intrinsic and directly related with the individual. Intrinsic factors can include the intensity of external sources, the directness of conflict and doubt.Factors that are related with the individual are motivations, characteristics, beliefs, cognitive resources and skills [25].

\section{Stress Results - Indicators}

Stress may have biological, emotional, mental, social, and spiritual consequences [26]. Usually the results are mixed, because the stress affects individuals as wholeness [27,28]. Biologically stress can even threaten homeostasis. Stress can cause negative emotions. Mentally can affect the perceptive and possibilities for problem solving. Socially can affect individual's relationships with others and spiritually stress can affect beliefs and moral values [29].

Reactions to stressful events are not necessarily damaging [30]. Situations that can create, a moderate to elevated level of emotional stimulation, are increasing individual's efficiency as they can revitalize it and cause feelings of satisfaction, joy, pleasure. When the emotional stimulation (whether it is positive or negative) reaches high levels, then it can affect the individual's efficiency and if it is held at high levels for a long time, can have negative health impacts [4].

Negative effects on health and performance can also have the very low levels of emotional intensity.It is a fact that people are more efficient during emotionally intense experiences that are faced as a "opportunities" or "challenges" [30].

There is indeed a critical boundary for each person beyond which, when emotional stimulation extends, the efficiency of the individual decreases, feels unproductive and often is, to a greater or lesser extent, disorganized. The extent of disorganization varies from person to person [3, 31]. According to observations that made on the reactions thatpeople have on critical situations (fire, flood, earthquake) showed that the $15 \%$ of people during a crisis can function effectively, a $70 \%$ rate is showing various degrees of disorganization but still are able to function with some effectiveness and a rate of $15 \%$ is totallydisorganized [4].

\section{Coping of Stress}

Coping of stress is described as the successful management of problems and stressful situations [24,26]. The coping strategy (coping mechanism) is defined as an innate or acquired response to a changing environment or to a specific problem or a situation [32]. According to Folkman and Lazarus, coping is the perceived and behavioral effort in order to adjust in specific external or internal requirements, which exceed the individuals' management resources [24].

Two types of coping strategies have been described [33, 34]:

Coping that is focusing in the problem (problem-focused coping):indicating to the efforts for improving some situation by creating changes or taking measures and

Emotional centered coping (emotion - focused coping): includes thoughts and actions that are relieving the feeling. This coping strategy does not improve the situation, but by using it the person feels better.

Coping strategies can also distinguished into long term and short term [35]. Long-term coping strategies can be realistic and constructive. Short-term coping strategies may temporarily reduce stress to a tolerable level, but they are inadequate ways of reality management. Furthermore the may have devastating effect on the individual [36].

Stress coping may be adaptive or maladaptive. Adaptive coping is what helps the individual to deal effectively with stressful events and to minimize the risk deriving from those, while maladaptive coping does not have any positive results in stress management [37].

The effectiveness of coping strategies that an individual may use depends on various factors such as the number, duration and intensity of stress sources, previous experiences of the individual, available support systems and the personal abilities [38].

If the duration of those stressors is extended and goes beyond the coping dynamic of the individual, that leads the person to exhaustion and develops a susceptibility to health conditions. Extended stress can also lead to mental disease [2].

As the coping and defense mechanisms strategies become ineffective, the individual may have difficulties in his interpersonal relationships, problems at work and significant reduction of abilities for addressing essential needs [4,39].

\section{Nursing Interventions for People that Experience's Stress}

Nurses, by recognizing the patient's needs and reactions, they should choose those interventions that it will be the most effective for the particular patient [40-44]. Most important intervention for alleviating stress are: anxiety reduction, anger management, relaxation and sleep, proper diet, physical exercise, relaxation techniques and effective time management [26,45 -47].

\subsection{Anxiety Reduction}

Nurses should take all necessary measures in order to reduce stress and anxiety that their patients experiencing [48]. For example, nurses could encourage patients to take a deep breath before an injection, provide the necessary information before a procedure and offer support to both patients and their families [49-52].Nurses are aware that direct interventions are necessary for preventing the spreadingof 
anxiety, in which an individual's anxiety may negatively effect and others around him such other patients, relatives evenhealth professionals [53-55].

\subsection{Anger Management}

Patients that are experiencing stress can often exhibit anger [56]. Managing a patients' anger is one frequent difficulty that nurses face [57.58]. Nursing care of the patients that are experiencing anger is mainly difficult for two reasons:

- Patients rarely are expressing their anger or the cause of it verbally. Instead they are usually refusing treatment, are becoming verbally aggressive, they are demanding and threaten to use violence. Their observations rarely are reflecting the cause of their anger [59].

- Patient's anger can often cause fear and anger to nurses. Thus, nurses are usually responding to it in such way that may increase patient's anger, as to the point of violence. Furthermore, nurses under such circumstances tend act in a way that reduces their own stress and not the patient's stress [60].

Healthcare professionals implementing anger management strategies in patients. Those strategies including understanding the reaction, acceptance of the patient's right to be angry, trying to communicate with the patient in order to identify sources and meaning of anger. Moreover, they apply interventions for reassuring, they use silence and time supply as therapeutic means and last in difficult situations of risk, they intervening in such way in order to ensure patient's, family members and staff's safety [61-65].

\subsection{Rest and Sleep}

Those are two important factors in stress management, because while the body is resting is retrieving the desired energy levels [66]. However, for enable patients to rest, some nursing interventions may be required to ensure comfort, potential pain management and promote to spiritual serenity [58.67].

\subsection{Nutrition}

A healthy diet is increasing body's resistance to stress [51]. In order to reduce negative effects of stress individuals should avoid substances such as caffeine, salt, sugar and fat and include in their diet enough vitamins and minerals [68].

\subsection{Physical Exercise}

A normal exercise can promote biological and emotional health $[14,43]$. The biological benefits are the improvement of muscle tone, cardiopulmonary function and weight control [4]. Psychological benefits are relieving from tension and relaxation [69]. Generally, health standards are recommending exercise at least three times a week for 30 to 45 minutes [34].

\subsection{Relaxation Techniques}

Many relaxation techniques can be used to relief stress
[70-73]. Nurses can teach those techniques to patients and encourage them to use when they facing stressful situations outside the hospital. Relaxation techniques that are often applied are breathing exercises, massage, progressive relaxation, guiding use of images, biofeedback, therapeutic touch, music therapy, humor and laughter and finally meditation [69,74-77].

\subsection{Management of Time}

People who manage their time properly are experiencing less stress because they feel that everything is under control [58]. Controlling other people's' demands is an important element in proper time management, because many times their demands cannot be addressed [59]. Sometimes people need to be taught which demands can fulfillwithout experiencing any stress, which to negotiate and which to reject [75].As it comes to time management it is important to consider, what goals can be achieved during the day and which during the week.In addition, it is necessary for people to consider what is important to them and what can be achieved [31].

\section{Conclusion}

For the last decades, the term of stress has enjoyed increasing popularity in the behavioral and health sciences and through the process of time; many treatments have been applied in an effort to address this complex health problem. Yet, we all have experienced stress in our lives some of us more and some less, in a matter of fact stress can be also useful, stimulating, and welcome.It is indeed a common experience, thus to address it doesn't necessarily needs the assistance of a specialist.

Its high frequency and the mixed forms in which it appears impose the need for every nurse and healthcare professional in general to assess patiently and with interesting the variety of issues that may contribute to its appearance such as family, professional and interpersonalproblems.

Nowadays nurses have in their possession and can choose through a variety of resources in order to help patients to cope stress. The implementation of proper nursing care and the psychological support for stress is always necessary, regardless of its causes.

\section{References}

[1] Peplau H. A working definition of anxiety. In : Burd SF., Marshall MA. Some clinical approaches to psychiatric nursing. New York: Macmillan, 1968.

[2] Raya A. Mental Health Nursing and Psychiatric Nursing. Athens, 1993.

[3] Marttin P., Long MV.,Poon LW. Age changes and differences in personality traits and states of the old and very old. The Journals of Gerontology 2002; 57B: 144-152.

[4] Manos N. Basics of clinical psychiatry. University Studio Press. Thessaloniki, 1988. 
[5] Selye H. Stress Syndrome. Am J Nurs 1965; 65(3): 97-99.

[6] Speileberg C. Anxiety and stress. Psychogios Editions. Athens, 1980.

[7] Holmes TS. Life situations and disease. J AcadPsychosom Med 1978; 19:747.

[8] Reynaud SN., Meeker BJ. Coping styles of older adults with ostomies. Journal of Gerontological Nursing 2002; 28(5): 3036 .

[9] Wu CY., Baig K., WichaikhumO. Coping behaviours of individuals with chronic obstructive pulmonary, disease. MedsurgNursing 2001;10: 315-320.

[10] Richardson C., Poole H. Chronic pain and coping: A proposed role for nurses and nursing models. Journal of Advanced Nursing 2001; 34: 659-667.

[11] Zook R. Learning to use positive defence mechanisms. American Journal of Nursing 1998; 98(3). 16B, F. H.

[12] Rogers CR. Client - centered therapy: It's current practice, implications and theory.Hougthon Mifflin. Boston, 1951.

[13] Schafer W. Stress management for wellness $-4^{\text {th }}$ ed. Stamford. CT: International Thomson Publishing, 2000.

[14] Logothetis I. Introduction in Psychiatry. $2^{\text {nd }}$ Edition, Thessaloniki, 1981.

[15] Selye H. The stress of life. New York: McGraw-Hill, 1956.

[16] Selye H. The stress of life (revised ed.). New York: McGrawHill, 1976.

[17] Selye H. Stress without distress. Lippincott: Philadelphia, 1974.

[18] Selye H. The stress of life. $2^{\text {nd }}$ ed. New York : Mc Gray - Hill, 1978.

[19] Lazarus RS. Stress and coping (3rd ed). New York: Columbia University Press, 1995.

[20] Lazarus RS. Psychological stress and coping process. Edit: Hill Book, N.Y., 1966.

[21] Lazarus RS., Launier R. Stress related transaction between person and environment. Edit :McGraw - Hill Book, N.Y., 1978.

[22] Lazarus RS. Coping and adaptation in health and illness. Edit : Free Press N.Y., 1983.

[23] Folkman S., Lazarus RS. Manual for the ways of copping Questionnaire. CA Consulting Psychologist Press, Palo Alto, 1988.

[24] FoLkman S., Lazarus RS. Coping and emotion. In A. Monat\& R. S., 1991

[25] Lazarus R.S., Folkman S. Stress appraisal and coping. New York, Springer, 1984.

[26] Fontana D.Anxiety and its coping. Methods of stress reducing. Hellenic Letters Editions. Athens, 1996.

[27] Hertig V. (2004) Stress, stress response, and health. Nursing Clinics of North America 2004; 39: 1-17.
[28] Lindop E. (1991). Individual stress among nurses in training: Why some leave while others stay. Nurse Education Today 1991; 11: 110-120.

[29] Hermes TH., Rahe RH. The social readjustment rating scale. Journal of Psychosomatic Research 1967; 11:213-218.

[30] Hanson PG. The joy of stress. Ontario : Hanson Stress Manag. Organ, 1985.

[31] MacGowan B. Self reported stress and its effects on nurses. Nursing Standard 2001; 15(42): 33-38.

[32] Gates DM. Stress and coping: A model for the workplace. AAOHN Journal 2001; 49: 390-398.

[33] Grandinetti DA. Two ways to beat stress. RN 2002; 65( 3): 47.

[34] GoldJ., Thornton L.Simple strategies for managing stress. RN 2001; 64(12): 65-68.

[35] Haber J., Hoskins P., Leach A., Sideleau B. Comprehensive Psychiatric Nursing. McGraw - Hill, New York, 1987.

[36] Grieve RJ. Day surgery preoperative anxiety reduction and coping strategies. British Journal of Nursing 2002; 11:670-673, 676-678.

[37] Keable D. The management of Anxiety. A guide for therapists. $2^{\text {nd }}$ Edition. Ed. Churchill Livingstone. New York, 1997.

[38] MonatA., Lazarus RS. Stress and coping- 3rd ed. New York: Columbia University Press, 1991.

[39] Skinner BF. Whatever happened to psychology as the swcience of behavior? American Psychologist 1987;42: 780786.

[40] Black JM., Matassarin JE. Nursing clinical management for continuity of care. $5^{\text {th }}$ ed., Saunders, Philadelphia, 1997.

[41] Edlim G., Golanty E., Brown KM. Health and wellness: A holistic approach (7th ed). Boston: Jones \& Bartlett, 2002.

[42] Papathanasiou I., Sklavou M., Kourkouta L. Holistic Nursing Care: Theories and Perspectives. American Journal of Nursing Science 2013; 2(1): 1-5.

[43] Jones I. How to assess stress: A significant step for nursing students. Journal of Nursing Education 1988; 27: 227-230

[44] Papathanasiou IV., Kleisiaris Ch., et al.Critical Thinking: The Development of an Essential Skill for Nursing Students. ActaInformaticaMedica 2014; 22(4): 283-286.

[45] Fontaine KL., Fletcher JS. Mental health nursing (5th ed.). Upper Saddle River. NJ: Pearson Education Inc, 2003.

[46] FreudS. Theegoandthemechanismsofdefence. NewYork: InternationalUniversitiesPress, 1946.

[47] GarpenitoLJ. Nursing diagnosis: Application to clinical practice (9th ed. \}. Philadelphia: Lippincott, 2001.

[48] Bigger T., Zimmerman R., Alpert G. Nursing, nursing education and anxiety. Journal of Nursing Education 1988; 27: 411-117.

[49] Biley FC. Nurses' perception of stress in preoperative surgical patients. Journalof Advanced Nursing 1989; 14: 575-581. 
[50] Carbee DD., Gentry JA. Coping with the stress of surgery. Association of Operating. Room Nurses Stress Journal 2001; 73: 946-951.

[51] Carr JA., Powers MJ. Stressors in associated with coronary bypass surgery. Nursing Research 1986; 35(4): 243-246.

[52] Walters. KL. SimoniJM. Reconceptualising Native women's health: An "indigenist" stress coping model. Journal of Public Health 2002; 92: 520-52.

[53] CarrieniV.L. Pathophysiological Phenomena in Nursing. C. West, 1989.

[54] GettrustKV.,Brade PD. Nursing Diagnostic Process and Clinical Practice: Guides of Nursing Care. EllinEditions. Athens, 1997.

[55] Gordon M. Manual of Nursing Diagnostic Process. Beta Editions. Athens, 2009.

[56] Campbell C. Crisis in care - stress survey, disturbing findings. Nursing Mirror 1985; 160: 16-24.

[57] Johnson M., Maas M., Moorhead S. Nursing outcomes classification (NOC) (2nd ed.). St. Louis. MO: Mosby, 2000.

[58] Plati C. Specific clinical problems: Nursing approach. Athens, 1998.

[59] Pianos KH. Counseling therapeutic dialogue: Theory and Practice. EllinEditions. Athens, 1998.

[60] NANDA International. NANDA nursing diagnoses: Definitions and classification 2003-2004. Philadelphia, 2003.

[61] Lango D. Communications and human behavior. In: LangoD.,Williams R. eds. Clinical practice in psychosocial nursing : Assessement and intervention. New York: AppletonCentury - Groffts, 1978.

[62] Kourkouta L., Papathanasiou IV. Communication in Nursing Practice. Materia Socio Medica 2014; 26(1): 65-67

[63] Luban BP., Walter P., Frieder KR., Kurt LH. The psychosomatic patient in daily medical practice. Parisianos Editions. Athens, 1997.
[64] Lunch SM., George LK. Interlocking trajectories of loss related events and depressive symptoms among elders. TheJournalsofGerontology 2002; 57B, S :117-125.

[65] Wilson-Barnett J. Stress in hospitalization: Patients Psychological Reaction to illness and Health care. Churcill Livingstone, Edinburg, 1979.

[66] McCloskey JC.,Bulechek GM. Nursing interventions classification(NIC) - 3rd ed. St. Louis MO: Mosby, 2000.

[67] Varcarolis E. Foundation of psychiatric-mental health nursing. Saunders, Philadelphia, 1990.

[68] Moulinos G. Nutrition for a better life; myths and truths, dietary recommendations and diets. PsychogiosEditions. Athens, 2013.

[69] Papathanasiou I., Kotrotsiou E. Alternative Methods of Pain Treatment. Hellenic Journal of Nursing 2000; 39(2): 131-138.

[70] Athanasiou E. Treatment of color and its application in painting. The new dimension of color in painting. Ellin Editions. Athens, 2002..

[71] Allen K., Shykoff B., Izzo J. Pet ownership, but not ACE inhibitor therapy, blunts home pressure responses to mental stress. Hypertension 2001, 38: 815.

[72] Amber RB. Colour therapy. N.M: Aurora Press, Santa Fe, 1983.

[73] Beck AT.Cognitive therapies and the emotional disorder. International University Press, New York, 1976.

[74] Loupasakis A. Laugh the best treatment. Kedros $2^{\text {nd }}$ Eidtion. Athens, 2002.

[75] Murray RB., Huelskoetter MM. Psychiatric mental health nursing - Giving emotional care. EnglewwodGliffs, N.J., 1983.

[76] Yurkovich E. (1989) Patient and nurse roles in the therapeutic community. Perspect Psychiatric Care 1989; 15(3): 18-22.

[77] Fradelos E., Komini A. The use of essential oils as a complementary treatment for anxiety. American Journal of Nursing Science. Special Issue: Mental Health Care: Aspects, Challenges and Perspectives .2015; 4(2-1):1-5. 